\title{
A Design of Low Power Electrolarynx with Glottal Modified Source
}

\author{
Madhushankara $\mathrm{M}^{1, *}$, Somashekara Bhat ${ }^{2}$ and Keerthana Prasad ${ }^{1}$ \\ ${ }^{1}$ School of Information Sciences, Manipal Academy of Higher Education, Manipal, India \\ ${ }^{2}$ Department of Electronics \& Communication, Manipal Institute of Technology, Manipal Academy of Higher Education, Manipal
}

Received 24 September 2018; Accepted 20 December 2018

\begin{abstract}
The larynx is a flexible part in the respiratory tract, a source of vibration during verbal communications. An electrolarynx or artificial larynx is a common device adopted by the laryngectomee to restore the speech. The objective of this paper is to design a low power electrolarynx using modified glottal source and perform an objective and subjective analysis of the vowel quality. In the first part, an electrolarynx circuit is designed which can drive different types of input signals. In the second part, a driving source is designed by pre-filtering the effect of neck surface. The power consumption of the prototype is measured and compared with the conventional type of electrolarynx. The vowel qualities are compared with that of normal vowels produced by a volunteer. We have found out that the glottal modified wave can reduce the power supply requirement of the electrolarynx. Loudness, quality factor and position of the formants are used as measures of quality for vowels produced by the present approach and found to be better (or comparable) than the traditional electrolarynx. When compared to existing method, the electrolarynx with glottal modified wave is power efficient and has a potential in forming a wearable device. It also has better vowel quality than the one with the conventional driving signal.
\end{abstract}

Keywords: Electrolarynx, Formants, Glottal source, Low power, Verbal communication

\section{Introduction}

The oral communications of a human being involves lungs, larynx, vocal tract, and mouth. The lungs provide the required energy to vibrate the larynx. The vibrations of larynx produces periodic waveform and termed as glottal wave, which acts as a source for speech production. The position of tongue, teeth and lips are responsible for the speech articulation [1-3].

The surgical removal of the larynx due to the circumstances such as laryngeal cancer terminates a person's ability to speak naturally [4]. Esophageal speech, Tracheoesophageal speech and electrolarynx are the three different methods to re-establish the voicing without the use of vocal chords and the space between them. In the esophageal speech, a person has to introduce air by swallowing air into esophagus region and release them abruptly to the oral cavity [5]. This causes the pharyngeal muscles to vibrate. This vibration is converted into speech by the articulators. It requires a high level of training and practice to succeed [6]. In tracheo-esophageal speech, a patient has to draw in air through a one way valve placed on a tracheal puncture [7]. The speech is formed by the articulators when this air directed to oral cavity by occluding the valve. This method suffers from hygienic issues such as fungal infections leading to leakage of fluids through tracheo-esophageal puncture [8]. The electrolarynx is an electro-mechanical vibrator which substitutes for larynx to reconstitute the speech. The device consists of a waveform generator and

*E-mail address: madhushankar.m@manipal.edu ISSN: 1791-2377 @ 2018 Eastern Macedonia and Thrace Institute of Technology. All rights reserved. doi:10.25103/jestr.116.11 vibrating head to be held against the neck when intended to speak. The vibrational energy of the device converts into acoustic energy and the speech is produced by the movement of articulators [9]. The electrolarynx is also helpful for the patients who are ill and under artificial ventilation [10-12].

The conspicuous appearance is one of the major drawbacks of electrolarynx. Due to its large size, the electrolarynx need to be hand held throughout the verbal communications which would cause lot of inconvenience and awkwardness to the user. Several miniaturization concepts are considered by researchers to make the patient's life easier. To reduce the size of the device, a thin vibrator [13] which can be attached to the neck surface with the help of a brace was designed. The transducer is controlled by the pocket sized wireless controller. Due to the requirement of a supply voltage of 9 $\mathrm{V}$, the entire system is still hefty. An electrolarynx YOUR TONE II is a wearable electrolarynx but its size and weight is not revealed in the literature [14]. A design of hands free operation [15] was developed by using a tiny pager motor. A thin polyethylene membrane attached to the motor, pulsates when a voltage is applied. The current handling capacity of the pager motors are generally low, resulting in insufficient vibration to produce the audible speech. The level of reduction in loudness affects the intelligibility of the speech $[16,17]$. A hands free design approach using a tiny transducer and a video camera to detect the lip movement thereby controlling the electrolarynx is at development stage and the audibility of the voice is not recorded [18]. The artificial larynx designed using mechanically driven gear has sub $100 \mathrm{~Hz}$ fundamental frequency range [19]. The low fundamental frequency would result in distracted voice output. 
Another disadvantage of electrolarynx is the distinctive voice quality due to the repeated vibration of the transducer and due to the improper delivery of the acceleration at the neck tissue. Noise radiation minimization, self-noise reduction and post processing of a-laryngeal speech are the methods to improve the speech intelligibility available in the literature. A normal glottal like signal to drive the electrolarynx [16] was employed along with a shield to cover the vibrator. The device was found to be bulky due to the protective covering of the electrolarynx.

The digital signal processing technique of spectral subtraction method to reduce the self-noise [20, 21], noise removal by the discrete cosine transform [22] with aim to improve the intelligibility of the speech. However, these methods cannot be employed when the background noise varies in magnitude. An adaptive filtering process is also carried out $[23,24]$ to remove the noise components. The efficiency of these algorithms tends to decrease when the estimation of noise reference signal becomes complex resulting in poor noise reduction [25]. The latest work on the device suggests the fundamental frequency variations to produce different tones for tonal languages [26-29]. However it requires an extensive training to produce variations in pitch.

Being a battery driven device the size of the electrolarynx should be as small as possible. But the battery technology is not advancing with the semiconductor technology, alternate methods of energy saving must be accommodated $[30,33]$. In this paper, we have addressed the problem of reducing the electrolarynx size and weight by decreasing the power consumption of the circuit. The reduction in the current requirement is achieved by modifying the excitation source. We have employed Li-ion batteries which have less weight and high capacity which further reduces the overall device size. The reduction of the size would lead to a wearable electrolarynx which eases the life of the patients. Apart from that, the modified excitation source improves the speech intelligibility when compared to the conventional source.

\section{Materials and Methods}

The following section discusses the design of electrolarynx and glottal modified wave.

\subsection{Proposed Electrolarynx}

The prototype of the electrolarynx circuit is represented in Fig. 1. A high capacity less weight Li-ion batteries are used to power the circuit. Two batteries are connected in series to form a maximum voltage of $8 \mathrm{~V}$ and a capacity of $860 \mathrm{mAh}$. A positive voltage regulator LM7805 is used to convert the battery voltage into $5 \mathrm{~V}$ and to supply a standalone microcontroller ATMEGA328P-PU. The network of R1 and $\mathrm{R} 2$ and operational amplifier U1 converts the stored digital values into analog signal. The value of $\mathrm{R} 1$ and $\mathrm{R} 2$ are $10 \mathrm{~K} \Omega$ and $20 \mathrm{~K} \Omega$ respectively. This signal excites the electrolarynx transducer using a class $\mathrm{AB}$ power amplifier formed by Q1 and Q2. This push pull combination of the amplifier is preceded by an operational amplifier U2 in voltage follower mode.

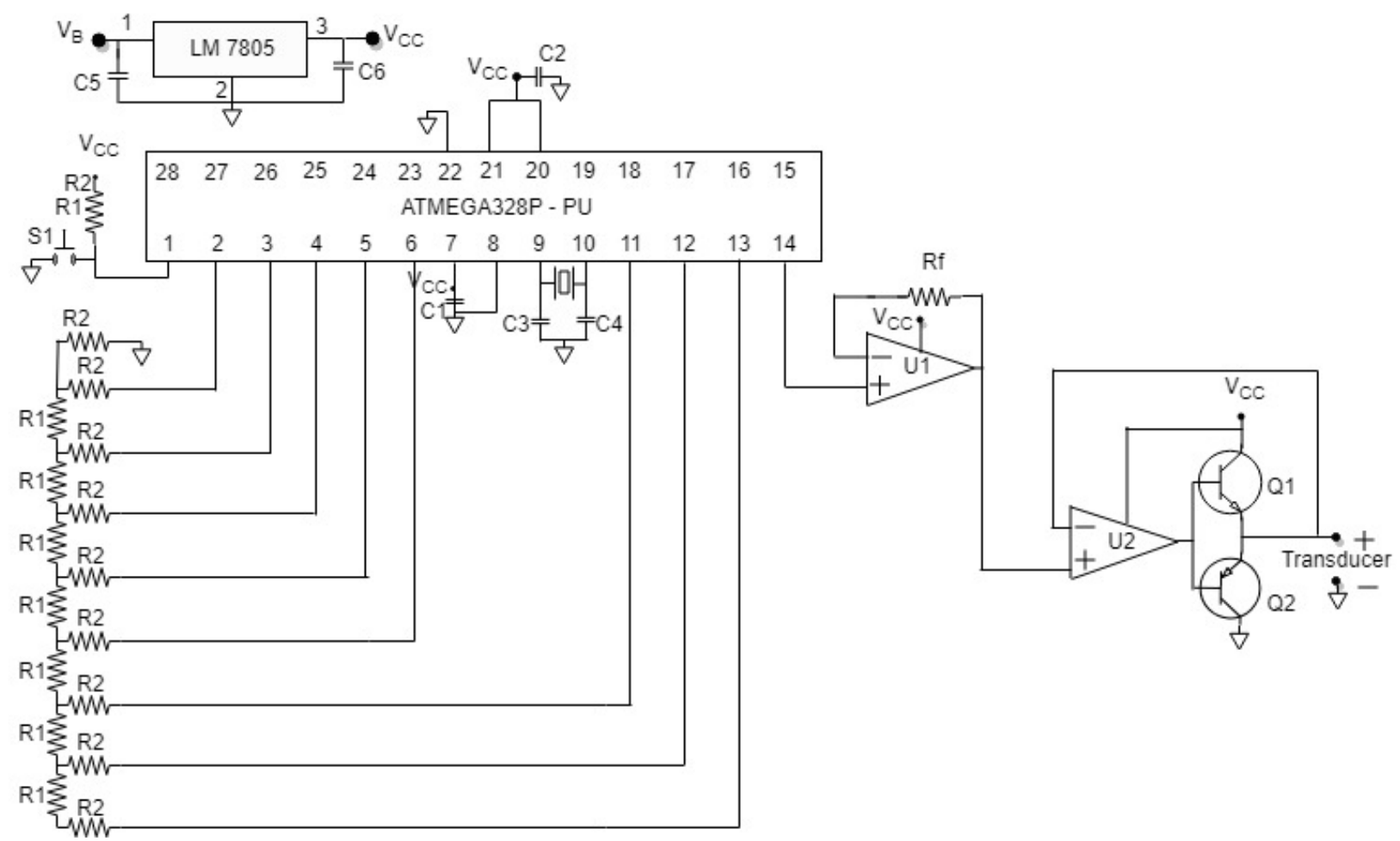

Fig. 1. Proposed electrolarynx circuit

\subsection{Design of Glottal Modified Wave}

This section discusses the designing of glottal modified wave from glottal wave.

\subsubsection{Glottal wave}

The glottal wave originates by the repeated vibrations of the larynx. It produces the volume velocity [34] to form speech excitation signal and it can be mathematically modelled by several ways which differ in their mathematical constructions. All such models were characterized as a quasi-periodic, always null, or positive wave. Fig. 2 shows a glottal wave with a fundamental frequency of $100 \mathrm{~Hz}$ generated using Rosenberg B model [35]. 


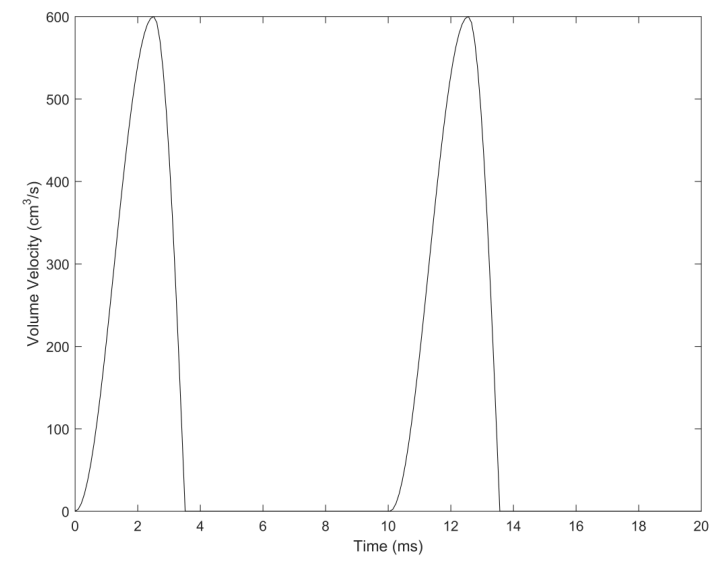

Fig. 2. Volume velocity of glottal wave

\subsubsection{Glottal modified source}

The electrolarynx is a device which drives excitation source external to the body more precisely on the neck surface. When this excitation signal reaches vocal folds, it deviates from its original shape because of the involvement of the neck surface of the user. Neck surface is a part of the system during vocalization in the case of an electrolarynx user. The neck transfer function is defined as the ratio of the volume velocity that excites the vocal tract to the acceleration measured at the neck surface. Neck transfer N(s) is represented as in Eq. (1) [36].

$$
N(s)=A * \frac{(s-z)^{2}}{\left(s-p_{1}\right)^{2} *\left(s-p_{2}\right)^{2}}
$$

Here, $\mathrm{A}$ is the gain, $\mathrm{z}$ is the location of zero, $\mathrm{p}_{1}$ and $\mathrm{p}_{2}$ are the locations of poles. The study conducted on a normal adult male reveal that, two zeroes are located at $120 \mathrm{~Hz}$, and double poles at $80 \mathrm{~Hz}$ and $1000 \mathrm{~Hz}$. The frequency response of neck transfer function is represented as discrete time system by using MATLAB and DSP System Toolbox Release 2014b, The MathWorks, Inc., Natick, Massachusetts, United States. It is plotted as in Fig. 3.

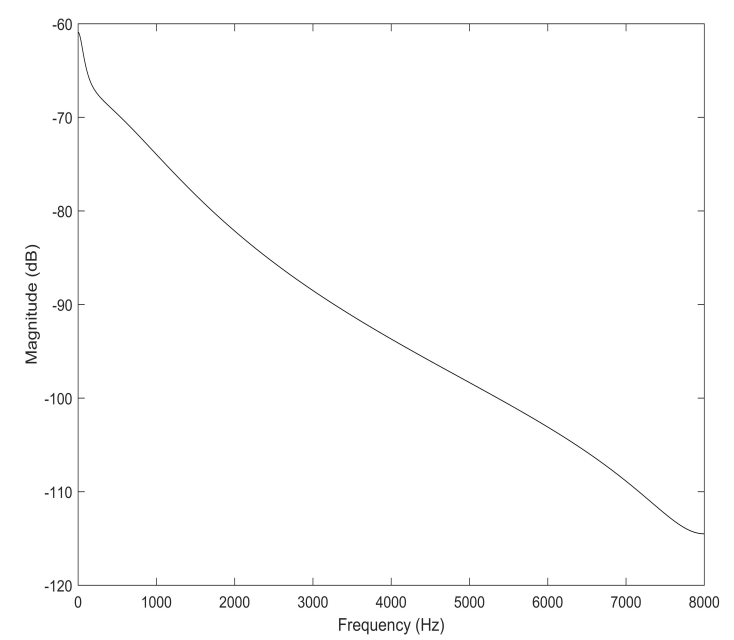

Fig. 3. Neck transfer function of a normal adult male

A glottal modified wave is designed by pre-filtering the glottal wave by the inverse of neck transfer function shown in Eq. (1). Fig. 4 represents a glottal modified wave for a normal adult male with a fundamental frequency of $100 \mathrm{~Hz}$.

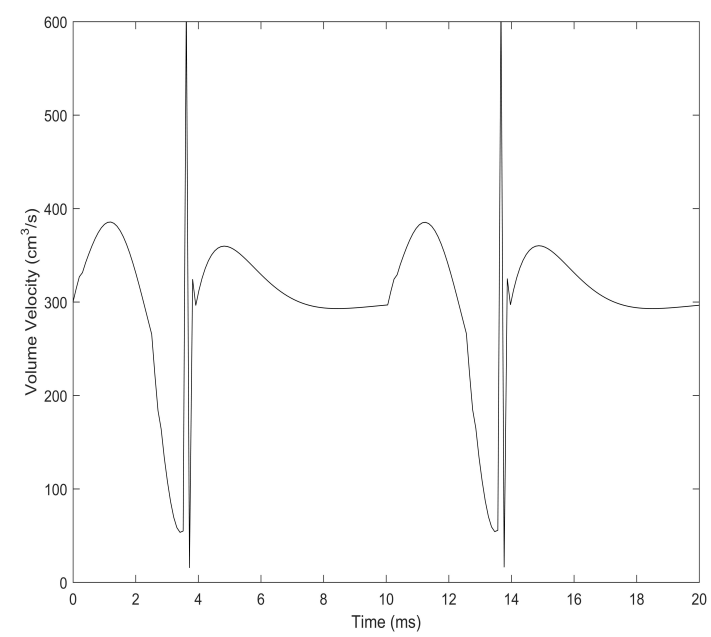

Fig. 4. Designed modified glottal airflow for a normal adult male

\subsection{Experimental Setup}

The binary values corresponding to the simulated glottal modified wave are stored in the flash memory of the 8-bit microcontroller shown in the proposed electrolarynx as a lookup table. It is programmed to generate an analog signal at a frequency of $100 \mathrm{~Hz}$. The power amplified signal is fed to a vibrator which acts as a transducer. The user has to configure his vocal tract to produce vowels when this transducer is held against the neck surface.

\section{Results}

An existing vibrating head from the commercially available Servox Digital Speech Aid is used as the transducer. This device uses square wave as the driving signal and has the facility to adjust the duty cycle to control the loudness of the voice generated. The vibrator is held against the neck and articulators are configured to produce the vowels. The sustained vowels are produced using both glottal modified wave and square wave. The speech generated by these two drive signals are recorded using speech recorder and digitized.

Initially, the measurements are performed to find the power consumed by the prototype. The drop in the supply voltage, and the current drawn by the device are measured as function of time. These readings are used to calculate the power consumed by the circuit. Then the experiment is repeated by using the conventional excitation source (square wave). The vowel qualities like formants, bandwidths and amplitudes are plotted and compared along with the normal vowel plot.

\subsection{Measurement of Voltage, Current and Power}

With aim of bringing down the size of the final device, Liion batteries, which have high capacity and less weight, are employed as a source power. Two batteries are connected in series to obtain the required voltage $(8 \mathrm{~V})$ across the terminals with the device under test as load. The system is kept ON continuously until the series voltage drops to $6 \mathrm{~V}$. A digital multimeter MAS830L is used to measure the current drawn by the load. The current drawn with various input patterns is observed throughout the procedure and tabulated as in Table 1 . 
Table 1 Current drawn by different methods

\begin{tabular}{|c|c|c|c|c|}
\hline \multirow{4}{*}{$\begin{array}{l}\text { Current } \\
\text { (A) }\end{array}$} & \multicolumn{4}{|c|}{ Input Pattern } \\
\hline & \multicolumn{3}{|c|}{$\begin{array}{l}\text { Square Wave } \\
\text { (Duty Cycle) }\end{array}$} & \multirow{2}{*}{$\begin{array}{c}\text { Glottal } \\
\text { Modified Wave }\end{array}$} \\
\hline & $(90 \%)$ & $(85 \%)$ & $(50 \%)$ & \\
\hline & 0.36 & 0.35 & 0.26 & 0.32 \\
\hline
\end{tabular}

The drop in the battery terminal voltage is noted down by connecting another digital multi meter in parallel with circuit at an interval of 20 minutes. The observed data is plotted as in Fig. 5.

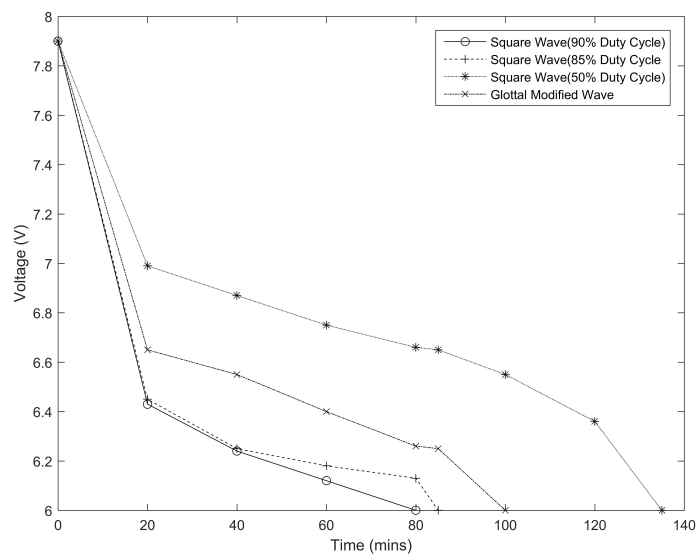

Fig. 5. Supply voltage reduction

The product of the voltage and current is plotted in Fig. 6 as the power consumed by the circuit.

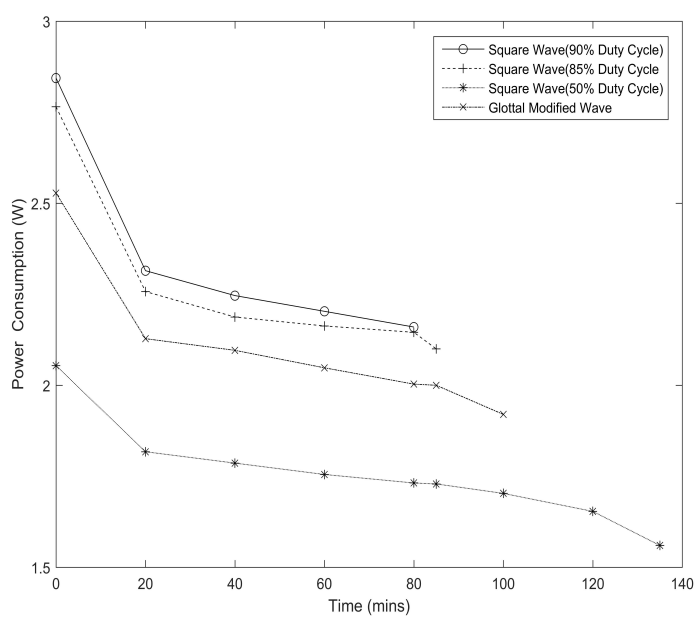

Fig. 6. Power consumption of the circuit

3.2 Measurement of Formants, Bandwidth, and Amplitude

A normal adult male sitting in a quiet room, pronounces the vowels /i/, /a/ and /u/ just like his usual speaking. Another three set of same vowels are recorded using the proposed electrolarynx circuit initially with square wave (with different duty cycles) and then with the glottal modified wave as the input. All these vowels are recorded using Voice Recorder application in Motorola Moto G3 device and saved as MPEG Audio Layer3 format. A Linear Predictive Coefficient analysis is performed on them using MATLAB with a coefficient of 12 which is represented in Fig. 7- Fig. 9.

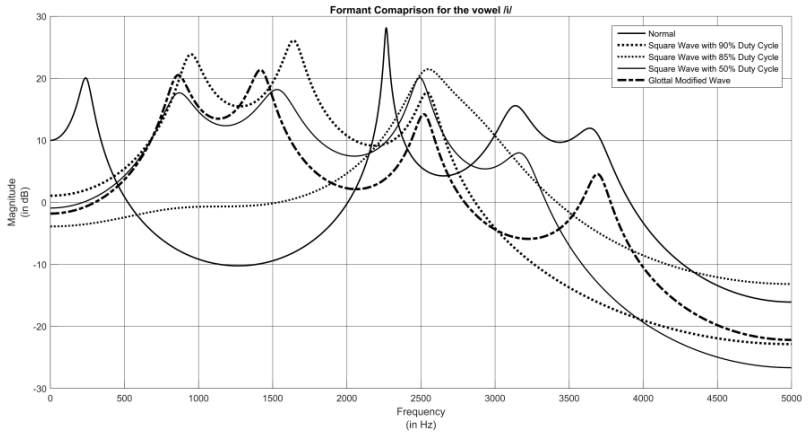

Fig. 7. Vowel formants of /i/

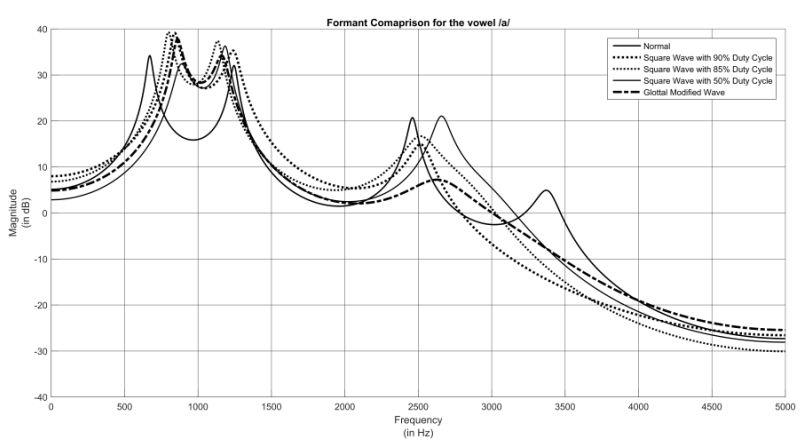

Fig. 8. Vowel formants of /a/

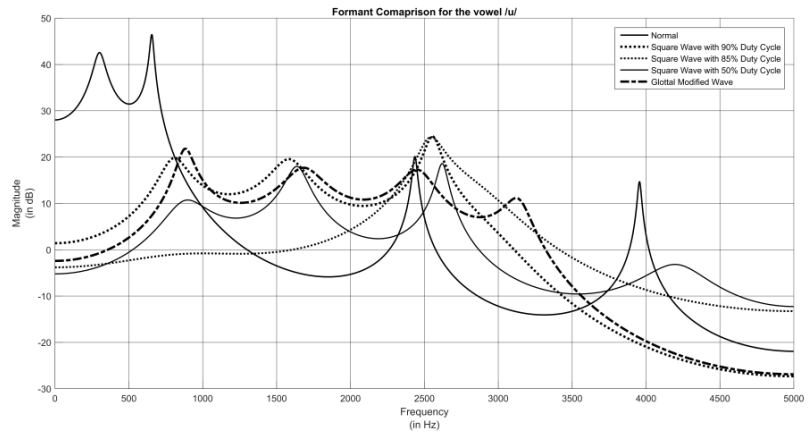

Fig. 9. Vowel formants of $/ \mathrm{u} /$

Using the formant frequencies, the Euclidian distance between the first two formants across the different type of vowel production are compared in Fig. 10. From the vowel plot, amplitude for the first two formants are plotted in Fig. 11 .

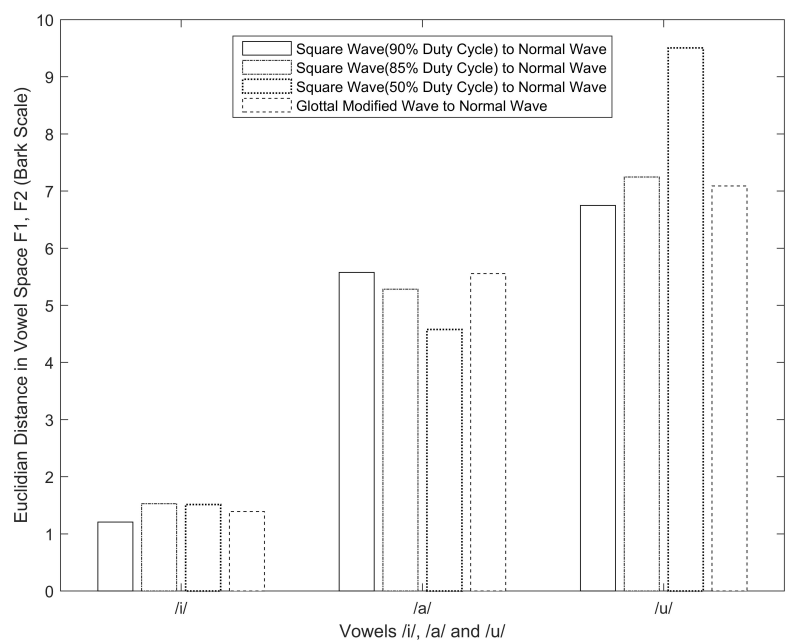

Fig. 10. Average Euclidian distance of $F 1$ and $F 2$ 


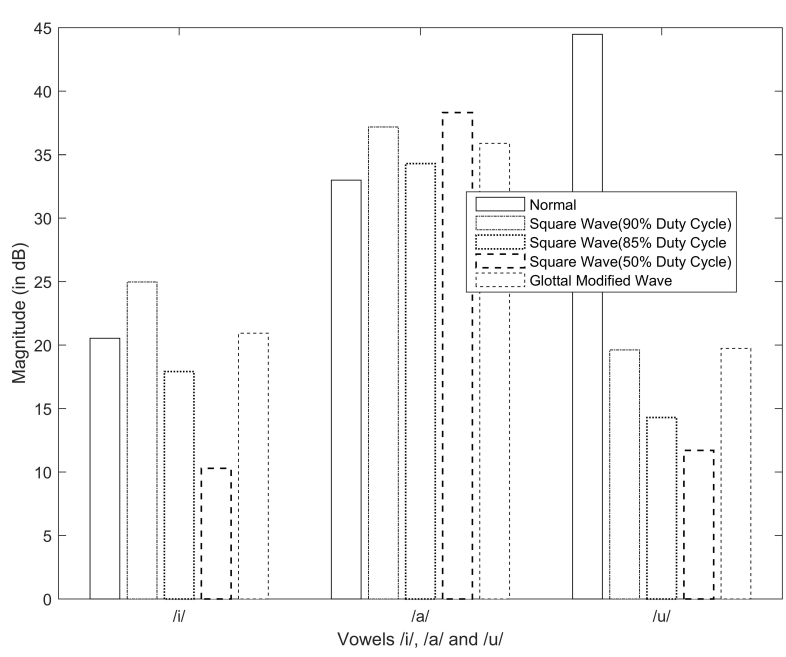

Fig. 11. Amplitude plot of formants for $/ \mathrm{i} /, \mathrm{a} / \mathrm{and} / \mathrm{u} /$

A ratio of formant frequency and bandwidth is called as quality factor. An average of $\mathrm{Fi} / \mathrm{BWi}$ for the first two formants is plotted in Fig. 12. Finally, the device leakage noise due to improper coupling of electrolarynx to the neck surface is measured for all the three methods and plotted in Fig. 13.

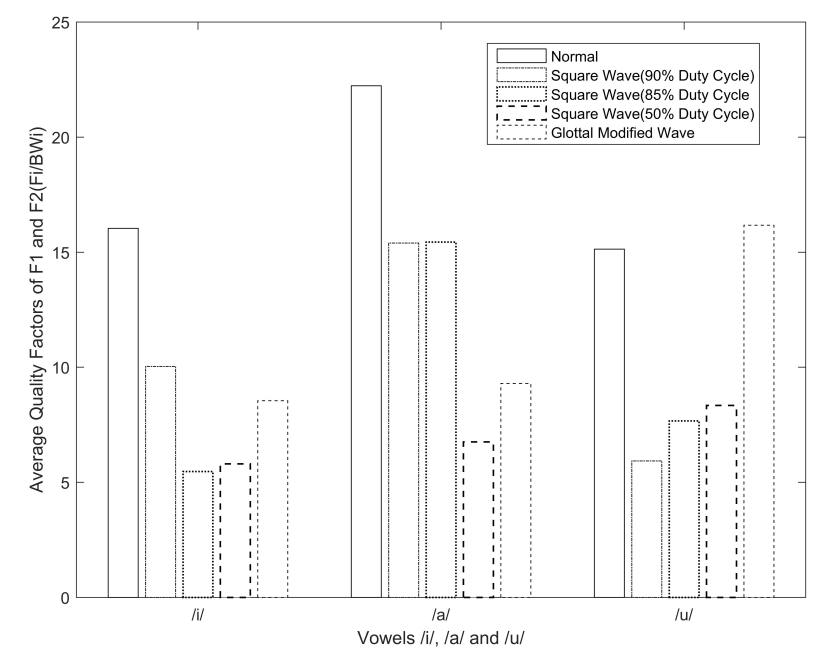

Fig. 12. Average quality factors for $/ \mathrm{i} /, / \mathrm{a} /$ and $/ \mathrm{u} /$

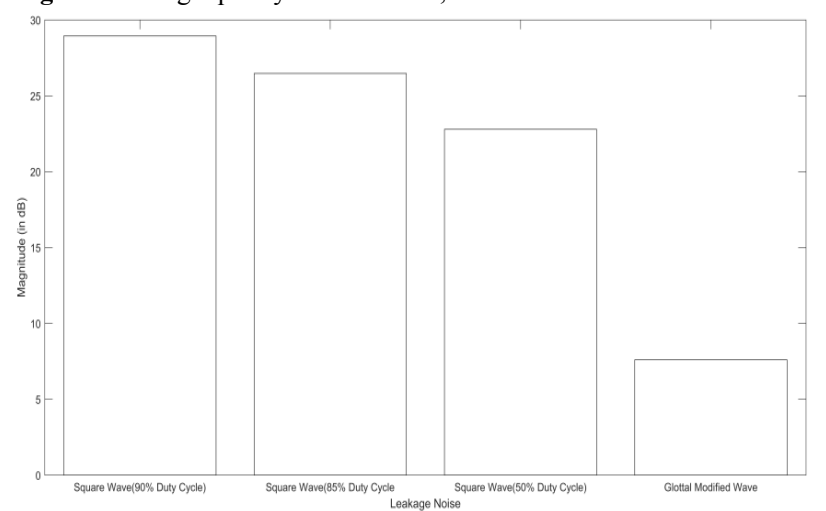

Fig. 13. Device leakage noise with different driving sources

\subsection{Subjective Analysis}

A GRBAS scale, which rates grade $(G)$, roughness $(R)$, breathiness (B), asthenicity (A), and strain (S) on a scale of 0 -3 where a value 0 means best score. The rating is made by assessing conversational speech or vowels. The perceptual evaluation of electrolarynx speech is assessed by grade $(G)$, which is the severity of hoarseness and relates to the overall voice quality.

A total of 15 voice samples are recorded consisting of normal vowel, electrolarynx vowel with square wave $(90 \%$, $85 \% \& 50 \%$ duty cycles) and glottal modified wave as the sources. A $10 \%$ of random repetition was included to enable the intra-judge reliability analysis. The auditory-perceptual voice grading was conducted by thirteen speech therapists with an average of 5 years of experience and familiar with GRBAS scale are tabulated in Table 2. After listening to each voice, each evaluator conducted the analysis individually and no information was shared among evaluators. Each vocal sample could be listened one more time on request. Evaluators were not aware of the patient diagnosis or the fact that individuals with no alteration in voice were included in the sample, as this could compromise their judgment.

Table 2: Evaluation of different vowels by grade

\begin{tabular}{|c|c|c|c|c|c|c|c|c|c|c|c|c|c|c|c|}
\hline \multirow{2}{*}{ Vowel } & \multicolumn{13}{|c|}{ Evaluators } & \multirow{2}{*}{ Mean } & \multirow{2}{*}{ SD } \\
\hline & 1 & 2 & 3 & 4 & 5 & 6 & 7 & 8 & 9 & 10 & 11 & 12 & 13 & & \\
\hline Normal_i & 0 & 0 & 0 & 0 & 0 & 0 & 0 & 0 & 0 & 0 & 0 & 0 & 1 & 0.077 & 0.266 \\
\hline $\mathrm{Sq} 90 \_\mathrm{i}$ & 2 & 2 & 2 & 1 & 2 & 2 & 1 & 2 & 3 & 2 & 2 & 3 & 3 & 2.077 & 0.615 \\
\hline Sq_85_i & 3 & 3 & 3 & 2 & 3 & 3 & 1 & 1 & 3 & 2 & 3 & 3 & 3 & 2.538 & 0.746 \\
\hline $\mathrm{Sq} 50 \_\mathrm{i}$ & 3 & 3 & 3 & 3 & 3 & 3 & 2 & 3 & 2 & 1 & 3 & 3 & 3 & 2.692 & 0.606 \\
\hline $\mathrm{Gm} \_\overline{\mathrm{i}}$ & 2 & 2 & 3 & 3 & 2 & 3 & 1 & 2 & 2 & 1 & 2 & 3 & 3 & 2.231 & 0.697 \\
\hline Normal_a & 0 & 0 & 0 & 0 & 0 & 0 & 0 & 0 & 0 & 0 & 0 & 1 & 2 & 0.231 & 0.576 \\
\hline Sq_90_a & 1 & 1 & 3 & 0 & 2 & 2 & 0 & 0 & 2 & 2 & 1 & 0 & 1 & 1.154 & 0.948 \\
\hline $\mathrm{Sq} \_85 \_\mathrm{a}$ & 1 & 1 & 3 & 2 & 3 & 3 & 0 & 2 & 3 & 1 & 1 & 1 & 2 & 1.769 & 0.973 \\
\hline $\mathrm{Sq} 50 \_\mathrm{a}$ & 2 & 2 & 3 & 1 & 3 & 2 & 1 & 1 & 3 & 1 & 3 & 1 & 2 & 1.923 & 0.828 \\
\hline Gm_a & 3 & 2 & 1 & 1 & 2 & 2 & 0 & 0 & 2 & 1 & 1 & 1 & 2 & 1.385 & 0.836 \\
\hline Normāluu & 0 & 0 & 0 & 0 & 1 & 1 & 0 & 0 & 1 & 0 & 0 & 0 & 1 & 0.308 & 0.462 \\
\hline $\mathrm{Sq} \_90 \_u$ & 2 & 1 & 2 & 0 & 2 & 2 & 2 & 2 & 3 & 2 & 2 & 3 & 3 & 2 & 0.784 \\
\hline $\mathrm{Sq} \_85 \_\mathrm{u}$ & 2 & 3 & 2 & 1 & 3 & 1 & 1 & 3 & 3 & 2 & 3 & 3 & 3 & 2.308 & 0.821 \\
\hline $\mathrm{Sq} \_50 \_\mathrm{u}$ & 3 & 2 & 2 & 2 & 3 & 2 & 1 & 2 & 3 & 2 & 3 & 3 & 3 & 2.385 & 0.625 \\
\hline $\mathrm{Gm} \_\bar{u}$ & 2 & 1 & 2 & 2 & 2 & 3 & 1 & 3 & 3 & 1 & 3 & 3 & 3 & 2.231 & 0.799 \\
\hline
\end{tabular}


A high degree of reliability was found between intra judge evaluations. The average measure Intra Correlation Coefficient was 0.9596 with a $95 \%$ confidence interval from 0.9215 to 0.9841 .

Analysis of variance (ANOVA) is conducted to determine whether there is any difference in normal and Electrolarynx vowels with following attributes.

Research Question: Is there any significant difference in the quality of vowel produced by the normal and electrolarynx?

Null hypothesis, HO: There is no significant difference in the quality of vowel produced by the normal and electrolarynx. Alternative hypothesis, $\mathrm{Ha}$ : There is a significant difference in the quality of vowel produced by the normal and electrolarynx.
Table 3 Results of analysis of variance of normal and electrolarynx vowels

\begin{tabular}{l|r|c|r|c|c|c}
\hline $\begin{array}{l}\text { Source of } \\
\text { Variation }\end{array}$ & SS & df & MS & F & $\begin{array}{c}\text { P- } \\
\text { value }\end{array}$ & $\begin{array}{c}\text { F } \\
\text { crit }\end{array}$ \\
\hline Between & 136. & 14 & 9.7 & 16.9 & $4 \mathrm{E}-26$ & 1.74 \\
Groups & 5 & & 52 & 8 & & 7 \\
Within & 103. & 180 & 0.5 & & & \\
Groups & 4 & & 74 & & & \\
Total & 239. & 194 & & & & \\
\hline
\end{tabular}

Table 3 represents the results of the one-way ANOVA of normal and electrolarynx vowels. It can be observed that $\mathrm{F}>$ $\mathrm{F}$ crit with a $\mathrm{p}$ value $<0.0001$. Therefore we reject the null hypothesis which states that there is no significant difference in the quality of vowels produced by the normal and electrolarynx. The mean value of grade from Table 2 is plotted in Fig. 14.

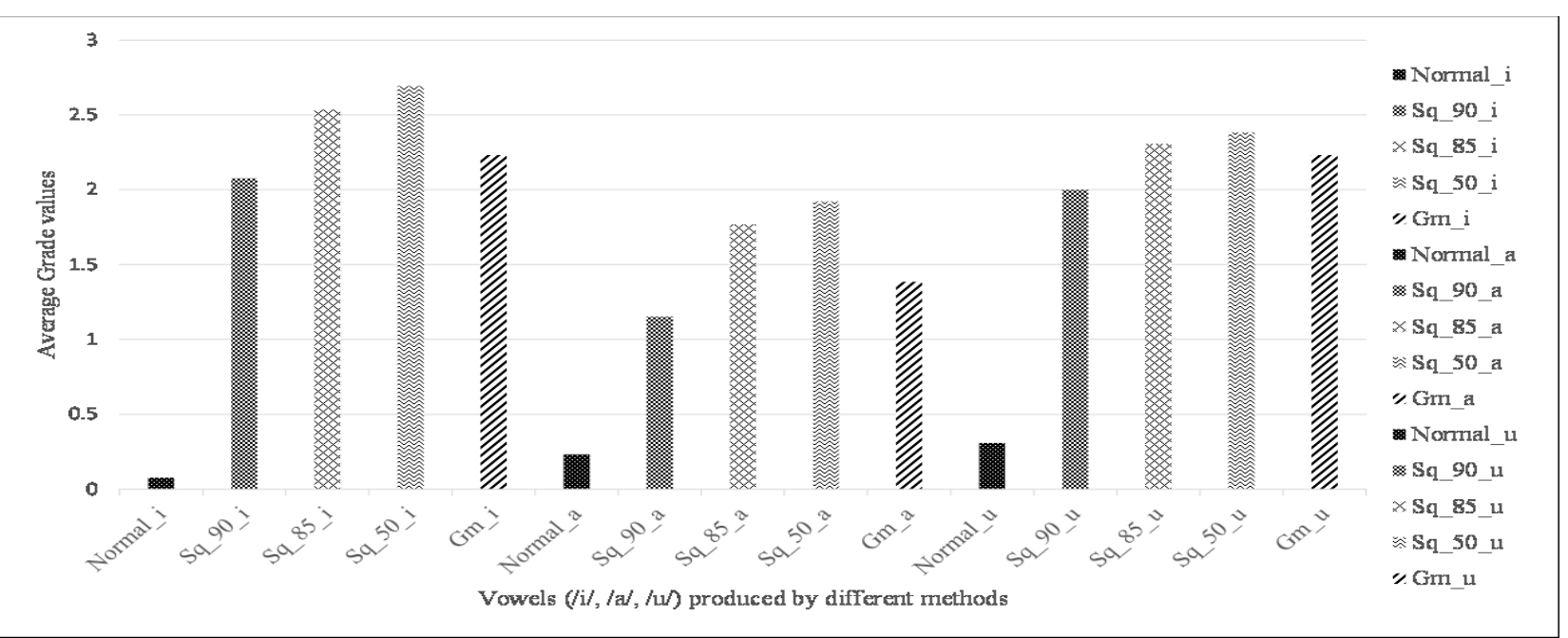

Fig. 14. Average value of grade of different vowels

\section{Discussion}

This work proposes an alternate driving signal for electrolarynx to reduce the power consumed by the circuit without compromising on the quality of the voice produced. With different input patterns, electrolarynx draws different amount of current. In the case of square wave, increasing the duty cycle to provide the louder voice increases the average current drawn, due to which battery discharges quickly. Features of this experiment are extracted from Fig. 7 to Fig. 13 and tabulated in Table 4.

Table 4 Characteristic Features Extracted from Fig. 7 to Fig. 13

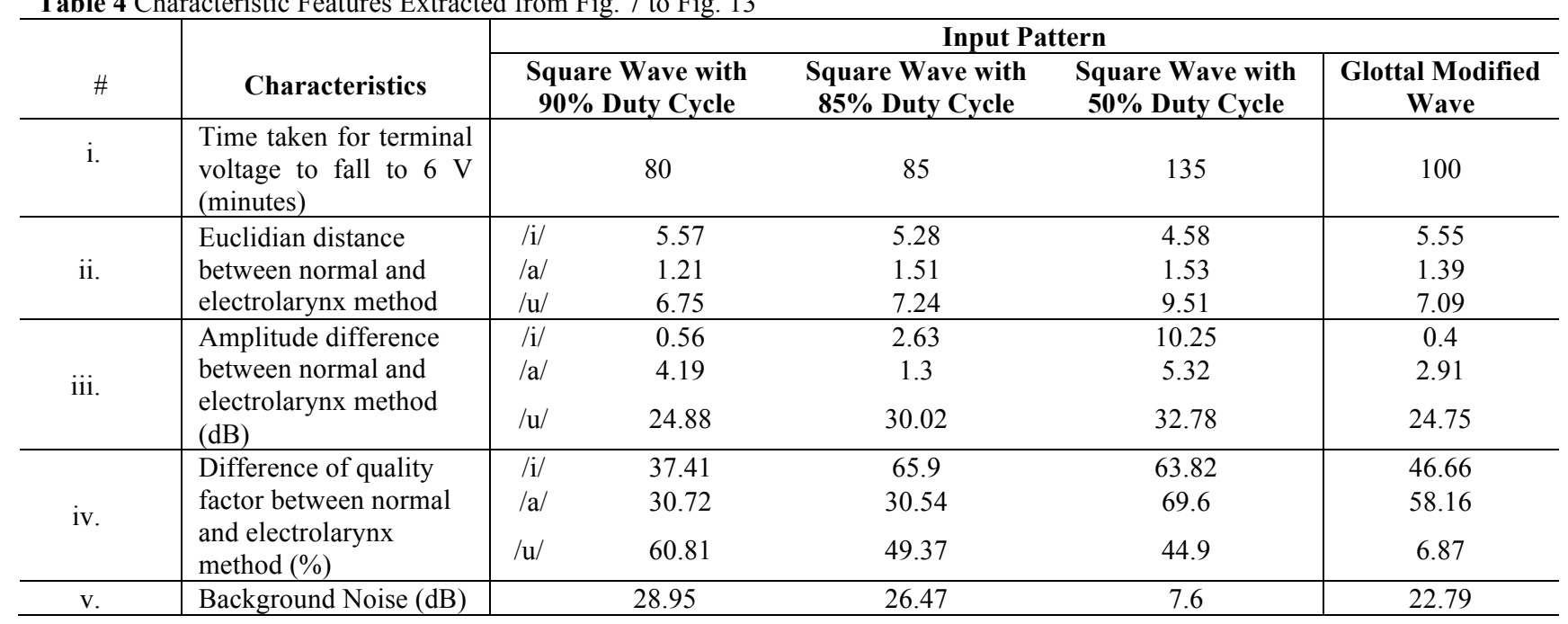


From the Table 4 following observations are derived.

a. When glottal modified waveform is used as input pattern, battery lasts longer than the square wave input with $90 \%$ and $85 \%$ duty cycles.

b. The vowel formants produced using glottal modified wave is closer to normal vowels than that of square waves.

c. The average difference in peak amplitude of the formant frequency is lesser when glottal modified wave is used when compared with all other square waves.

d. The quality factor of formant frequencies is better with glottal modified wave when compared to square waves of different duty cycles.

e. The back-ground noise (signal generated when the device is powered with no lip movement) is less for glottal modified wave when compared to that of square waves.

It can be observed from the Fig. 14 that the normal vowels have least score as expected. The scores of electrolarynx vowels differ in its values and showed a ranking of square wave with $90 \%$ duty cycle, glottal modified wave, square wave with $85 \%$ duty cycle and square wave with $50 \%$ duty cycle in the ascending order for all the three vowels. However when the statistical analysis test is conducted between electrolarynx vowels, the result is not significant which means there is no significant difference in the quality of vowels produced by the electrolarynx with different input sources.

\section{Conclusion}

In this paper, we have discussed how a glottal modified wave acting as the drive signal to electrolarynx would result in power efficiency with improved (or comparable) performance in terms of Euclidian distance, vowel amplitude, quality factor, background noise and perceptual evaluations. To evaluate the effectiveness of the proposed wave, it is compared with the user's original voice as well as with the conventional method of electrolarynx. The objective comparison of vowels reveals that our method is better with respect to battery performance and vowel quality. The less leakage noise provides greater comfort to the listener. Overall, a better electrolarynx is designed with a size promising towards forming a wearable speech aid.

In addition, the present work is carried out using an Arduino Uno development board which comprises of 20 pin Dual Line Package chip. The board consists of few additional components which are not needed for the present work. The components such as timers, brown-out detect circuits, analog to digital converters, light emitting diode indicators which draw a steady current of $50 \mathrm{~mA}$ when powered on leading to additional draining of the battery. The design and development of an Application Specific Integrated Circuit (ASIC) with lesser pin count and components will certainly bring drown the quiescent current and improve the battery performance.

This is an Open Access article distributed under the terms of the Creative Commons Attribution License

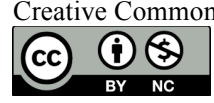

\section{References}

[1] S. R. Ventura, D. Freitas, and J. M. R. Tavares, "Application of MRI and biomedical engineering in speech production study," Computer methods in biomechanics and biomedical engineering, vol. 12, no. 6, pp. 671-681, 2009.

[2] K. Likitsupin, P. Punyabukkana, C. Wutiwiwatchai, and A. Suchato, "Acoustic-phonetic approaches for improving segmentbased speech recognition for large vocabulary continuous speech," Engineering Journal, vol. 20, no. 2, pp. 179-197, 2016.

[3] N. Ponchai, J. Phraeknanthoe, and C. Ratanasumawong, "Spur and Helical Gear Sliding Loss Model with Load Distribution Pattern on Gear Tooth Surface," Engineering Journal, vol. 22, no. 2, pp. 101$115,2018$.

[4] Z. Milutinovic, "Substitute laryngeal voice sources after partial laryngectomies," Logopedics Phoniatrics Vocology, vol. 21, no. 34, pp. 143-148, 1996.

[5] I. Hočevar-Boltežar and M. Žargi, "Communication after laryngectomy," Radiology and Oncology, vol. 35, no. 4, 2001.

[6] P. V. Pawar, S. I. Sayed, R. Kazi, and M. V. Jagade, "Current status and future prospects in prosthetic voice rehabilitation following laryngectomy," Journal of cancer research and therapeutics, vol. 4, no. 4, p. 186, 2008.

[7] M. Quer, J. Burgués-Vila, and P. García-Crespillo, "Primary tracheoesophageal puncture vs esophageal speech," Archives of Otolaryngology-Head \& Neck Surgery, vol. 118, no. 2, pp. 188$190,1992$.

[8] K. Izdebski, C. G. Reed, J. C. Ross, and R. L. Hilsinger, "Problems with tracheoesophageal fistula voice restoration in totally laryngectomized patients: a review of 95 cases," Archives of Otolaryngology-Head \& Neck Surgery, vol. 120, no. 8, pp. 840845, 1994.

[9] T. A. Bohnenkamp, T. Stowell, J. Hesse, and S. Wright, "Speech breathing in speakers who use an electrolarynx," Journal of Communication Disorders, vol. 43, no. 3, pp. 199-211, 2010.
[10]P. Tuinman, S. Ten Hoorn, Y. Aalders, P. Elbers, and A. Girbes, "The electrolarynx improves communication in a selected group of mechanically ventilated critically ill patients: a feasibility study," Intensive Care Med, vol. 41, no. 3, pp. 547-548, 2015.

[11]K. Sato, M. Okajima, and T. Taniguchi, "The electrolarynx as a communication tool for mechanically ventilated critically ill patients: a prospective feasibility study," Intensive care medicine, vol. 42, no. 8, p. 1299, 2016.

[12]L. Rose et al., "Feasibility of the electrolarynx for enabling communication in the chronically critically ill: The EECCHO study," Journal of Critical Care, 2018.

[13] M. Hashiba, Y. Sugai, T. Izumi, S. Ino, and T. Ifukube, "Development of a wearable electro-larynx for laryngectomees and its evaluation," in Engineering in Medicine and Biology Society, 2007. EMBS 2007. 29th Annual International Conference of the IEEE, 2007, pp. 5267-5270: IEEE.

[14] M. Hashiba, Y. Sugai, and T. Ifukube, "OS3-2 Commercialization of the multi-functional electro-larynx YOUR TONE II and it's further development for hands-free operation (OS3: Rehabilitation Devices I)," in The Proceedings of the Asian Pacific Conference on Biomechanics: emerging science and technology in biomechanics 2015.8, 2015, p. 81: The Japan Society of Mechanical Engineers.

[15]B. Madden, M. Nolan, T. Burke, J. Condron, and E. Coyle, "Intelligibility of Electrolarynx Speech using a Novel Hands-Free Actuator," 2011.

[16]A. W. Knox and M. Anneberg, "The effects of training in comprehension of electrolaryngeal speech," Journal of Communication Disorders, vol. 6, no. 2, pp. 110-120, 1973.

[17] M. S. Weiss, G. H. Yeni-Komshian, and J. M. Heinz, "Acoustical and perceptual characteristics of speech produced with an electronic artificial larynx," The Journal of the Acoustical Society of America, vol. 65 , no. 5, pp. 1298-1308, 1979.

[18]Y. Matsunaga, K. Matsui, Y. Nakatoh, and Y. O. Kato, "Development of Hands-free Speech Enhancement System for Both 
EL-users and Esophageal Speech Users," in International Symposium on Distributed Computing and Artificial Intelligence, 2017, pp. 334-341: Springer.

[19]T. G. Tuttle and B. D. Erath, "Design and Evaluation of a Mechanically Driven Artificial Speech Device," Journal of Medical Devices, vol. 12, no. 1, p. 011002, 2018.

[20] S. S. Pratapwar, P. C. Pandey, and P. K. Lehana, "Reduction of background noise in alaryngeal speech using spectral subtraction with quantile based noise estimation," in Proc. of 7th World Multiconference on Systemics, Cybernetics and Informatics SCI,(Orlando, USA, 2003), 2003.

[21]M. Haque and K. Bhattacharyya, "Speech Background Noise Removal Using Different Linear Filtering Techniques," in Advanced Computational and Communication Paradigms: Springer, 2018, pp. 297-307.

[22]R. Kabir, A. Greenblatt, K. Panetta, and S. Agaian, "Enhancement of alaryngeal speech utilizing spectral subtraction and minimum statistics," in Machine Learning and Cybernetics, 2008 International Conference on, 2008, vol. 7, pp. 3704-3709: IEEE.

[23]C. Y. Espy-Wilson, V. R. Chari, J. M. MacAuslan, C. B. Huang, and M. J. Walsh, "Enhancement of electrolaryngeal speech by adaptive filtering," Journal of Speech, Language, and Hearing Research, vol. 41, no. 6, pp. 1253-1264, 1998.

[24]H.-J. Niu, M.-X. Wan, S.-P. Wang, and H.-J. Liu, "Enhancement of electrolarynx speech using adaptive noise cancelling based on independent component analysis," Medical and Biological Engineering and Computing, vol. 41, no. 6, pp. 670-678, 2003.

[25]H. Liu and M. L. Ng, "Electrolarynx in voice rehabilitation," Auris Nasus Larynx, vol. 34, no. 3, pp. 327-332, 2007.

[26]L. Guo, K. F. Nagle, and J. T. Heaton, "Generating tonal distinctions in Mandarin Chinese using an electrolarynx with preprogrammed tone patterns," Speech communication, vol. 78, pp. 34-41, 2016.

[27]T. Ifukube, "Assistive Tool Design for Speech Production Disorders," in Sound-Based Assistive Technology: Springer, 2017, pp. 169-197.
[28]L. Wang, Y. Feng, Z. Yang, and H. Niu, "Development and evaluation of wheel-controlled pitch-adjustable electrolarynx," Medical \& biological engineering \& computing, vol. 55, no. 8, pp. 1463-1472, 2017.

[29]L. Wang, Y. Feng, Z. Yang, and H. Niu, "Development and perceptual evaluation of pitch controllable electrolarynx," in Biomedical \& Health Informatics (BHI), 2017 IEEE EMBS International Conference on, 2017, pp. 305-308: IEEE.

[30] M. Madhushankara, K. Prasad, C. Chaitanya, and S. Bhat, "A low power low frequency oscillator for driving Electrolarynx," in VLSI Systems, Architecture, Technology and Applications (VLSISATA), 2015 International Conference on, 2015, pp. 1-3: IEEE.

[31]A. K. Fuchs, M. Hagmüller, and G. Kubin, "The New Bionic Electro-Larynx Speech System," J. Sel. Topics Signal Processing, vol. 10, no. 5, pp. 952-961, 2016.

[32]H. Sood, V. M. Srivastava, and G. Singh, "Advanced MOSFET Technologies for Next Generation Communication SystemsPerspective and Challenges: A Review," Journal of Engineering Science \& Technology Review, vol. 11, no. 3, 2018.

[33] M. Hebali, D. Berbara, M. Benzohra, D. Chalabi, A. Saïdane, and A. B. Bey, "MOSiC $(3 \mathrm{C}, 4 \mathrm{H}$ and $6 \mathrm{H})$ Transistors $130 \mathrm{~nm}$ by BSIM3v3 Model in Low Voltage and Low Power," Journal of Engineering Science and Technology Review, vol. 10, no. 5, pp. 195-198, 2017.

[34]D. G. Childers, "Glottal source modeling for voice conversion," Speech communication, vol. 16, no. 2, pp. 127-138, 1995.

[35]M. Brookes, "VOICEBOX: A speech processing toolbox for MATLAB. 2006," URL http://www. ee. ic. ac. uk/... hp/staff/dmb/voicebox/voicebox. html. Available online, 2003.

[36]G. S. Meltzner, J. B. Kobler, and R. E. Hillman, "Measuring the neck frequency response function of laryngectomy patients: Implications for the design of electrolarynx devices," The Journal of the Acoustical Society of America, vol. 114, no. 2, pp. 10351047, 2003. 